An official publication of the International Society for Energy, Environment and Sustainability (ISEES)
Journal of Energy and
Environmental Sustainability
Journal homepage : www.jees.in

\title{
Performance and Emission Characteristics of Biodiesel Fueled Hydrogen Addition Engine Using EGR Technique
}

\author{
Karrthik R S* \& Baskaran S
}

Department of Mechatronics, Bannari Amman Institute of Technology, Erode, India

\section{A R T I C L E I N F O}

Received : 25 August 2017

Revised : 22 October 2017

Accepted : 02 November 2017

Keywords:

Biodiesel; Pongamia pinnata; Hydrogen;

Manifold induction; Emission;

\begin{abstract}
A B S T R A C T
In recent decades, the use of conventional fuels have increased dramatically due to the demand by the automotive and industrial sector. In order to overcome the depleting fossil fuels, alternative fuel is considered as an option, which could reliable source in the upcoming decades. Pongamia pinnata could an ideal alternative source for the production of biodiesel; hydrogen is expected to be an attractive clean alternative fuel in the near future to meet the stringent emission norms. This study investigated the performance and emission characteristics of four stroke single cylinder compression ignition engine with Pongamia pinnata biodiesel as an injected and hydrogen as an inducted fuel with EGR. In order to improve the performance of the engine, the experiment was conducted for different flow rate of hydrogen induction in the intake manifold with different EGR ratios. The performance and emission parameters were investigated with biodiesel fueled CI engine with variable flow rate of hydrogen induction with different EGR ratios. Results showed that the brake thermal efficiency was reduced by $1.31 \%$ and the emissions such as NOx, HC, CO were decreased by $2.22,10.52$ and $95.45 \%$, respectively for $10 \%$ EGR at full-load conditions with 10 LPM of hydrogen induction, when compared with diesel operation.
\end{abstract}

\section{Introduction}

The three principal global issues are global warming, air contamination, and fossil fuel dependency. All studies indicate that fossil fuel reserves are being depleted at an alarming rate. Biodiesel is prepared from edible and non-edible vegetable oils which considerably reduces the $\mathrm{CO}_{2}$ emission when compared to diesel and also it acts as promising fuels in the upcoming decades. The collective solution for the global warming is to find a viable alternative fuel in the form of hydrogen based energy from wind, biomass and other renewable sources (Song and Song 2015). Diesel engines have higher thermal efficiency and emit less $\mathrm{CO}_{2}$ than gasoline engines, thereby becoming an attractive choice. However, diesel engines emit high levels of NOx and smoke. New technologies are being developed to reduce these emission levels (Shin et al 2011, Sandalc and Karag•oz 2014). Many techniques have been developed to meet the restricted emission legislation for the competitive fuel economy, reduce exhaust gas after treatment emissions, and establish optimal combustion. However, the success of these methods is uncertain (Agarwal et al 2011).Biodiesel is produced from sources such as vegetable oils, animal fats or used cooking oils by a process called transesterification. It is an attractive fuel for diesel engines because of its high oxygen content, which enhances its burning efficiency (Boulifi et al 2010, Chaichan and Al Zubaidi 2012). Biodiesel combustion also emits less hydrocarbon (HC), carbon monoxide (CO), and particulate matter (PM) than diesel. However, biodiesel has lower heat content than diesel resulting in less power, torque, and fuel economy. Furthermore, oxygenated fuels, such as biodiesel, tend to increase nitrogen oxide (NOx) emissions. B100 (100\% biodiesel) increases NOx emissions by approximately $10 \%$ (Chaichan 2015, Lin and Lin 2007). Hydrogen is being recognized as an essential energy carrier for sustained power utilization because it has less negative effect on the environment than commonly used fuels. Hydrogen burning does not produce dangerous substances, such as, $\mathrm{HC}, \mathrm{CO}$ and sulfur oxides, natural acids or carbon dioxide $\left(\mathrm{CO}_{2}\right)$ (Antunes et al 2009). Sometimes, diesel fuel is difficult to ignite, which diminishes the output power. Elimination of the misfire phenomenon can improve the discharged emissions, performance, and fuel economy by adding hydrogen. Numerous researchers have sought to take advantage of the unique properties of hydrogen by adding it to diesel fuel to improve combustion specifications and reduce emissions. Saravanan et al (2008) concluded that NOx levels are reduced by utilizing EGR for different diesel engine loads by burning diesel blended with hydrogen, comparable outcomes were produced by other studies. However, their concentrates seemed to diminish the NOx outflows caused by adding hydrogen. The change in NOx levels by EGR was contrasted with that in the NOx levels of pure diesel burning without EGR. Liew et al. (2012), Ghazikhani et al. (2010) and Pradeep and Sharma (2007) reported that adding high rates of EGR to hydrogendiesel or biodiesel dual fuel engines reduced NOx and PM concentrations remarkably. Thus, in general, there are not many reports to study the impact of EGR's temperatures on the resulting engine performance and exhaust pollutants, despite the importance of this factor. Hence, we decide to study this.

\footnotetext{
* Corresponding Author: karrthik1312@gmail.com
} 


\section{Material and Methods:}

Experiments were carried out using four -stroke, single cylinder and stationary compression ignition engine at a constant speed of $1500 \mathrm{rpm}$ with the rated power of $5.2 \mathrm{KW}$. The engine temperature is correctly maintained by water-based coolant system. The principle of recirculating the exhaust gases back into the inlet manifold is termed as EGR technique. The exhaust gases mixes with the clean air and gets diluted with the intake charge which in turn acts as diluents and reduces the peak combustion temperature which spontaneously reduces the NOx formation. The experimental set-up for the EGR technique is depicted in Figure 1 . The fabrication is done using a designed aluminum chamber. The EGR temperature is reduced to $20-30{ }^{\circ} \mathrm{C}$. The system is designed to give $30 \%$ of EGR at maximum. The electronic control valve is used to control the EGR flow. The water-based cooling system is used as shown in Figure 2. In the air intake manifold, the hydrogen gas was inducted from a high pressure cylinder $(150 \mathrm{bar})$. Using a pressure regulator the inducted hydrogen gas pressure was maintained at 1 bar, which was capable of handling pressure up to 280 bar of inlet pressure and 14 bar of outlet pressure. The mass flow rate of hydrogen gas was controlled using a needle valve with a flow range of 0-30 LPM. The hydrogen flow meter worked on the principle of rotameter. The non- return valve was fixed at two dissimilar locations to avoid the back flow of hydrogen gas inside the cylinder. The flame trap was positioned in order to avoid the straight contact of flame with the hydrogen supply line and to quench the fire from the intake manifold in case of backfire. The flame arrester was used to suppress back fire by quenching hydrogen gas into water. The flame trapper and flame arrester with non- return valves were used to ensure the shelter of the experimental set-up. The load was measured by using eddy current dynamometer. The performance parameters were measured by the use of DAQ (Data Acquisition System). To measure the various emission parameters, the setup was equipped with AVL gas analyzer.

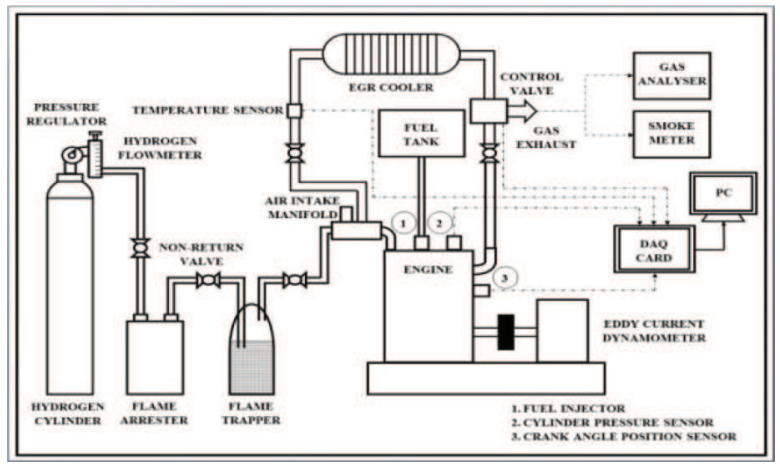

Fig. 1 Functional diagram of EGR set-up

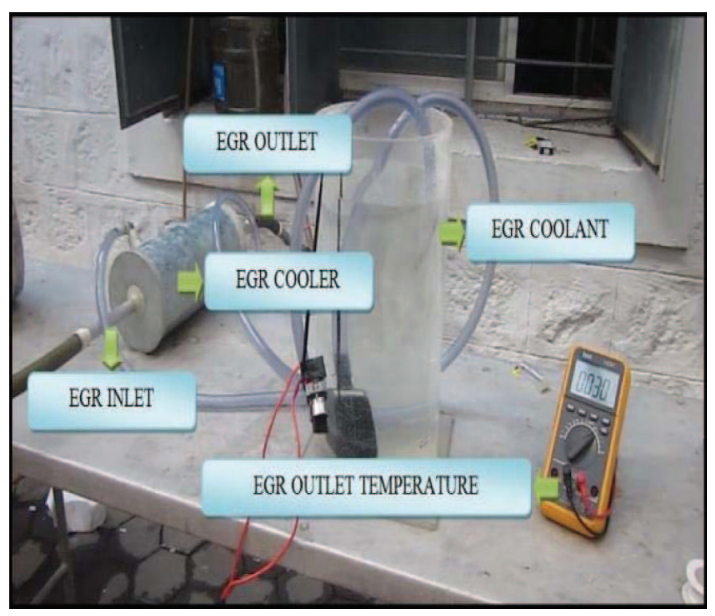

Fig. 2 Pictorial view of EGR set-up

The first phase of experimental work was done with the engine running completely on Pongamia pinnata biodiesel as the main fuel. The engine was operated for about 15 minutes at variable loads to attain the steady state conditions. The readings of difference in liquid in the manometer, time for $10 \mathrm{cc}$ fuel utilization of biodiesel, exhaust gas temperature, HC, $\mathrm{CO}, \mathrm{NOX}$ emissions and EGR ratios were calculated to investigate the performance and emission characteristics of a compression ignition engine. The analysis was done with different loading conditions from 0 to $100 \%$ at the sampling rate of $20 \%$. The second phase of experimental work was done by starting the engine initially with biodiesel and later varying the percentage of hydrogen induction (2 LPM, 4 LPM, 6 LPM, 8 LPM and 10 LPM) and the percentage of EGR $(10 \%, 20 \%$ and $30 \%)$ recirculated. The engine was permitted to run for about 15 minutes to attain the steady state conditions. The readings were then noted by repeating the same procedure at different loading conditions.

\subsection{Instrumentation}

The speed and crank position of the engine was measured by the use of rotary encoder. The pressure oscillation inside the cylinder during the combustion of fuel mixtures was measured by the use of pressure transducer. The rotary encoder and pressure sensor were linked to a computer-based data acquisition system. The cylinder pressure was monitored by the use of piezoelectric sensor. With the use of robust integrated high-temperature cable, the sensor was connected to the charge amplifier. The pressure range of this sensor was from 0 to 200 bar. To measure the inlet air, exhaust gas and EGR temperature three KType thermocouples were used. The thermocouples were coupled to digital indicators for temperature measurements. The gaseous emission was measured by the use of AVL combustion emission bench II. It composed of six gas specific analyzers. The hot gases from the exhaust pipes were sampled by passing it through headline filters. The emissions such as $\mathrm{NO}_{\mathrm{x}}, \mathrm{CO}, \mathrm{CO}_{2}$ and $\mathrm{HC}$ were measured using the AVL testing bench. The smoke level was measured using AVL 437C Smoke meter. The instrumentation setup consisted of computer based data acquisition system recognized as "Engine soft", which was used to obtain data and information from the engine.

\section{Results and Discussions}

In this work, the performance and emission characteristics of compression ignition fueled by using $P$. pinnata biodiesel with varying hydrogen mass flow rates and with varying EGR rate were studied. The brake thermal efficiency decreased with increase in the amount of EGR 10, 20 and 30\%, respectively as shown in Figures $3 \mathrm{a}$ to $3 \mathrm{c}$. The $10 \%$ EGR induction reduced the brake thermal efficiency. The brake thermal efficiency for $100 \%$ load was $30.13 \%$ at 10 LPM. An EGR induction of $20 \%$ with hydrogen induction at 10 LPM for biodiesel-fueled engine reduced the brake thermal efficiency compared with $10 \%$ EGR.. The brake thermal efficiency for $100 \%$ load was $29.07 \%$ at 10LPM. An EGR induction of $30 \%$ reduced the brake thermal efficiency to a very low value. The brake thermal efficiency for $100 \%$ load was $28.98 \%$ at 10 LPM. The optimal value was 10 and $20 \%$ EGR because the brake thermal efficiency reduced further lower with $30 \%$ EGR. The 10\% EGR induction reduced the brake thermal efficiency. The brake thermal efficiency for $100 \%$ load was $30.13 \%$ at 10 LPM. An EGR induction of $20 \%$ with hydrogen induction at 10 LPM for biodiesel-fueled engine reduced the brake thermal efficiency compared with $10 \%$ The brake thermal efficiency for $100 \%$ load was $29.07 \%$ at 10 LPM. An EGR induction of $30 \%$ reduced the brake thermal efficiency to a very low value. The brake thermal efficiency for $100 \%$ load was $28.98 \%$ at 10 LPM, respectively. The optimal value was $10 \%$ and $20 \%$ EGR because the brake thermal efficiency reduced further lower with $30 \%$ EGR.

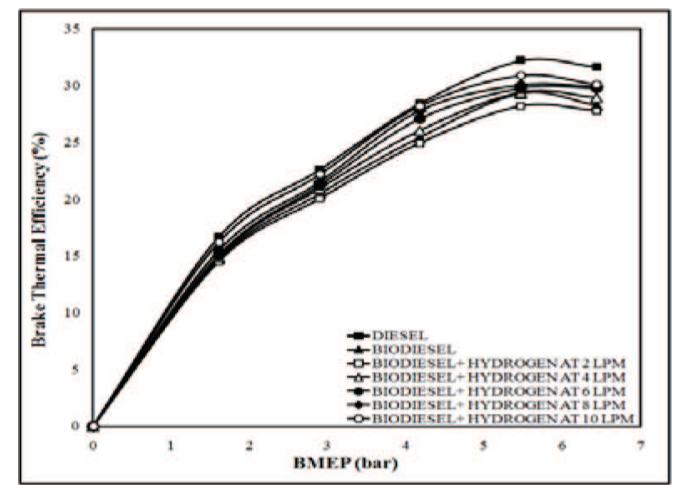

Fig. 3a BMEP vs BTE for biodiesel with hydrogen induction for $10 \%$ EGR 


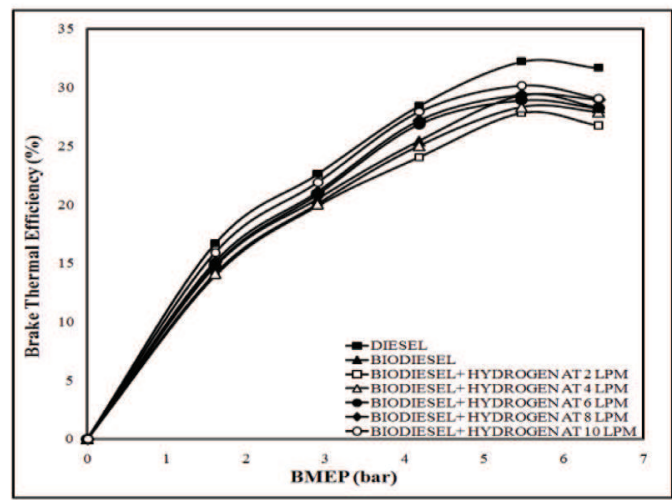

Fig. 3b BMEP vs BTE for biodiesel with hydrogen induction for $20 \%$ EGR

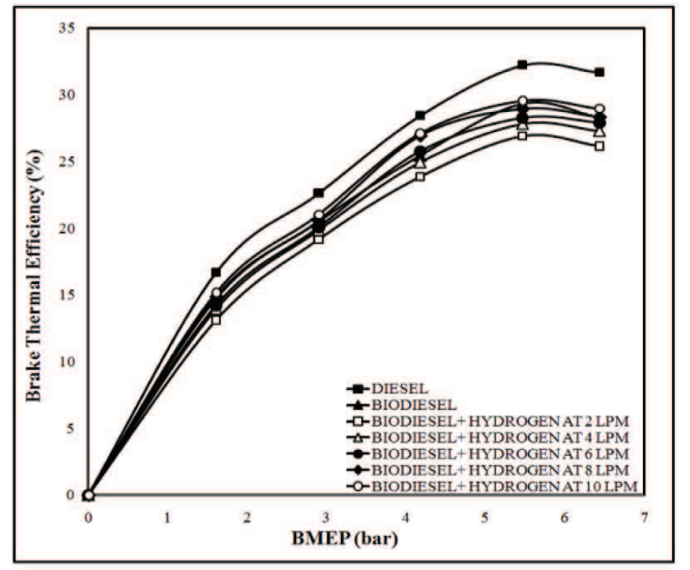

Fig. 3c BMEP vs BTE for biodiesel with hydrogen induction for $30 \%$ EGR

The brake thermal efficiency for $100 \%$ load was $29.07 \%$ at 10LPM. An EGR induction of $30 \%$ reduced the brake thermal efficiency to a very low value. The brake thermal efficiency for $100 \%$ load was $28.98 \%$ at $10 \mathrm{LPM}$. The optimal value was 10 and $20 \%$ EGR because the brake thermal efficiency reduced further lower with $30 \%$ EGR. The brake thermal efficiency of $10 \%$ of EGR with hydrogen induction was $30.92 \%$ at $80 \%$ load similar to brake thermal efficiency of diesel, which was $32.23 \%$ at same loading conditions. So the increase in EGR amount would ultimately decrease the brake thermal efficiency due to lack of oxygen during combustion.

An induction of $10 \%$ EGR with biodiesel and hydrogen induction increased the brake specific energy consumption compared with other fuels. As shown in Figure 4a, the energy consumption for 100\% load with $10 \mathrm{LPM}$ was $11948.22 \mathrm{~kJ} / \mathrm{kWh}$. The $20 \%$ EGR induction increased the energy consumption further compared with 10\% EGR induction. As shown in Figure $4 \mathrm{~b}$, the energy consumption was $12383.90 \mathrm{~kJ} / \mathrm{kWh}$ for $100 \%$ load at 10 LPM. The energy consumption for biodiesel with hydrogen induction for $30 \%$ EGR consumed more energy compared with all other conditions. The reason for reduction of brake specific fuel consumption was complete combustion occurring in dual fuel operation of hydrogen induction with biodiesel.

Exhaust temperature is the temperature produced due to combustion in the engine. EGR reduced the combustion rate. The cold EGR was used in this experiment. EGR temperature was reduced to 30ÚC with the help of water- based cooling system. A $10 \%$ EGR with hydrogen induction at 10 LPM for biodiesel provided 485ÚC at full-load conditions. An induction of $20 \%$ EGR with hydrogen induction at 10 LPM for biodiesel provided 465 ÚC at full-load conditions. 30\% of EGR induction with hydrogen induction at 10 LPM for biodiesel provided 419ÚC at full-load conditions. The EGR technique decreased the exhaust temperature due to the minimum amount of oxygen during combustion and caused lower energy released by hydrogen.

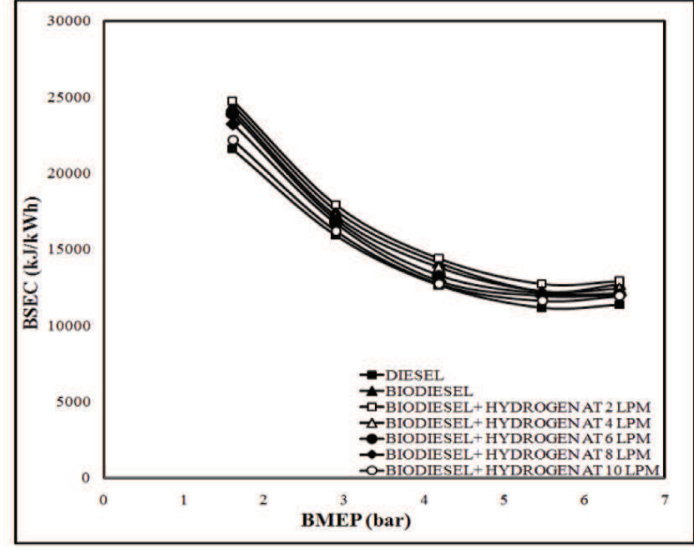

Fig. 4a BMEP Vs BSEC for biodiesel with hydrogen induction for $10 \%$ EG

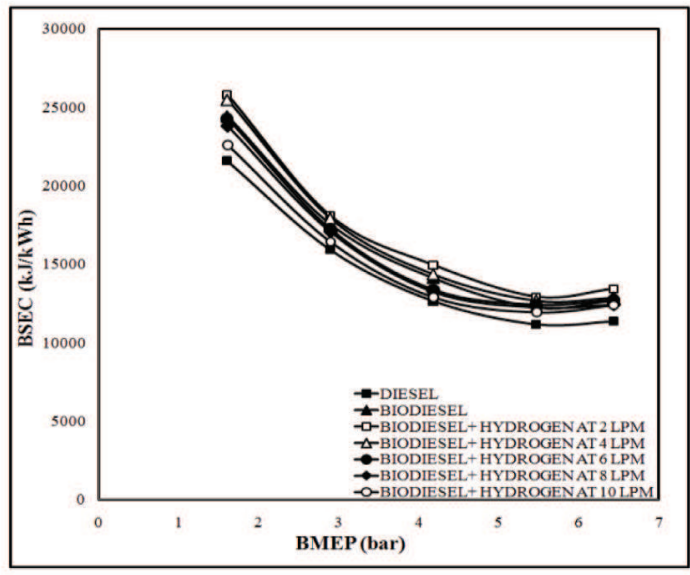

Fig. 4b BMEP Vs BSEC for biodiesel with hydrogen induction for $20 \%$ EGR

EGR is one of the emission reduction techniques for NOx in internal combustion engines. Cold EGR is used for safety as hydrogen is also inducted in the same air intake manifold. Hydrogen induction to the biodiesel-fueled engine with 10\% EGR decreased the NOx emission due to lower peak combustion temperature as shown in Figure 5a. A maximum NOX of 615 ppm could be obtained at 100\% load for 10 LPM hydrogen induction with $10 \%$ EGR. Hydrogen induction to the biodiesel-fueled engine with $20 \%$ EGR decreased the combustion temperature further than $10 \%$ EGR. Figure $5 \mathrm{~b}$ shows the variation in NOx emission for hydrogen induction with $20 \%$ EGR. Hydrogen induction at 10 LPM provided 607

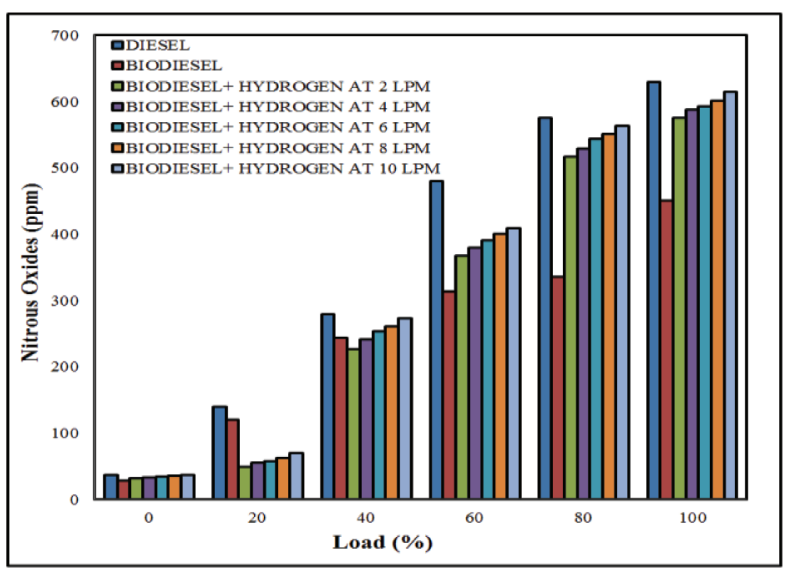

5a Load $\mathrm{Vs} \mathrm{NO}_{\mathrm{x}}$ for biodiesel with hydrogen induction for 10\% EGR 
ppm at $100 \%$ load, respectively. Figure $5 \mathrm{c}$ illustrated the $\mathrm{NO}_{\mathrm{x}}$ emission for $30 \%$ EGR with hydrogen induction. A maximum $\mathrm{NO}_{\mathrm{x}}$ of $593 \mathrm{ppm}$ was obtained at $100 \%$ load for 10 LPM hydrogen induction with $30 \%$ EGR.

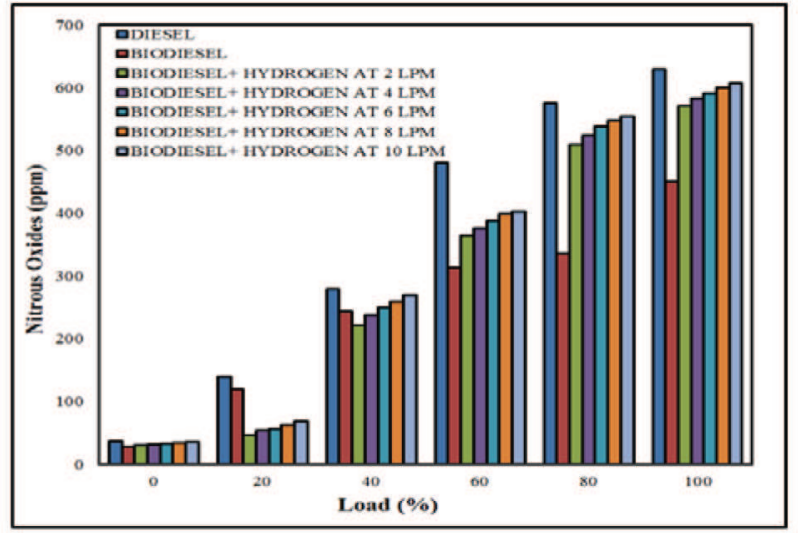

Fig. $5 b$ Load $\mathrm{Vs} \mathrm{NO}_{\mathrm{x}}$ for biodiesel with hydrogen induction for $20 \%$ EGR

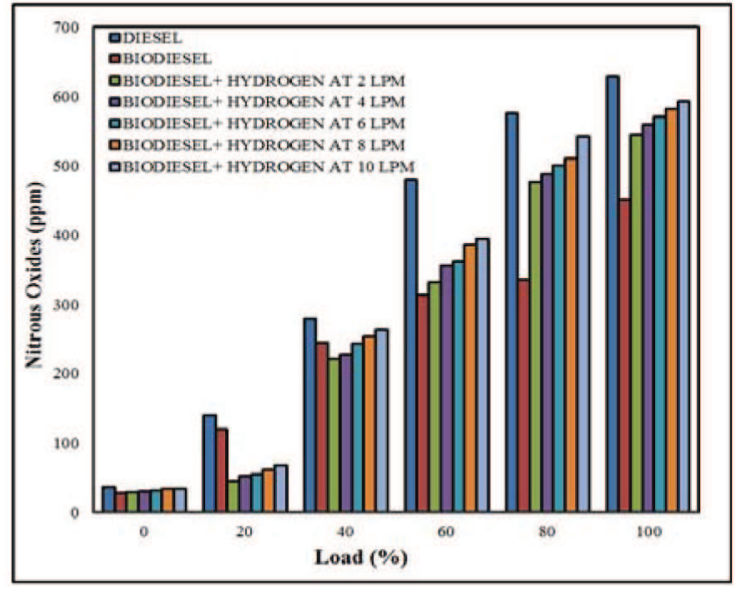

Fig. 5c Load $\mathrm{Vs} \mathrm{NO}_{\mathrm{x}}$ for biodiesel with hydrogen induction for $30 \%$ EGR

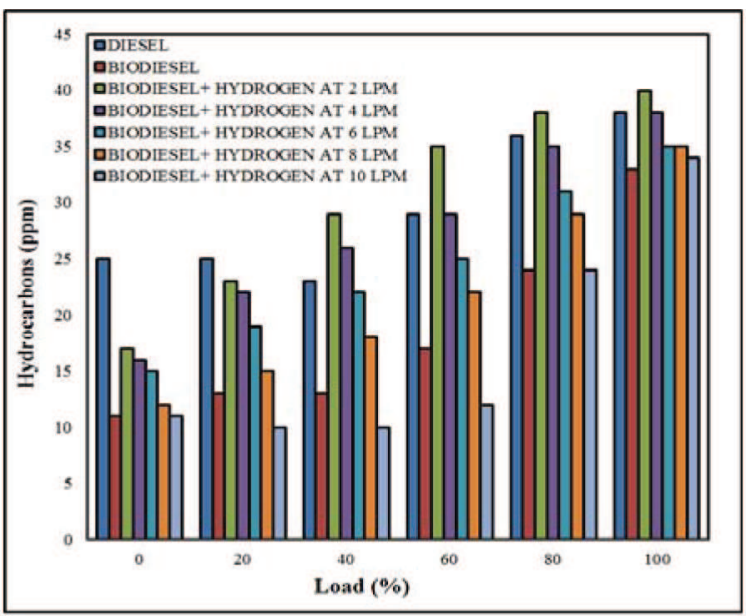

Fig. 5d Load Vs HC for biodiesel with hydrogen induction for $10 \%$ EGR

The formation of NOx greatly depends upon the combustion temperature. After the addition of hydrogen, the combustion temperature increases with increased $\mathrm{NOx}$ formation.

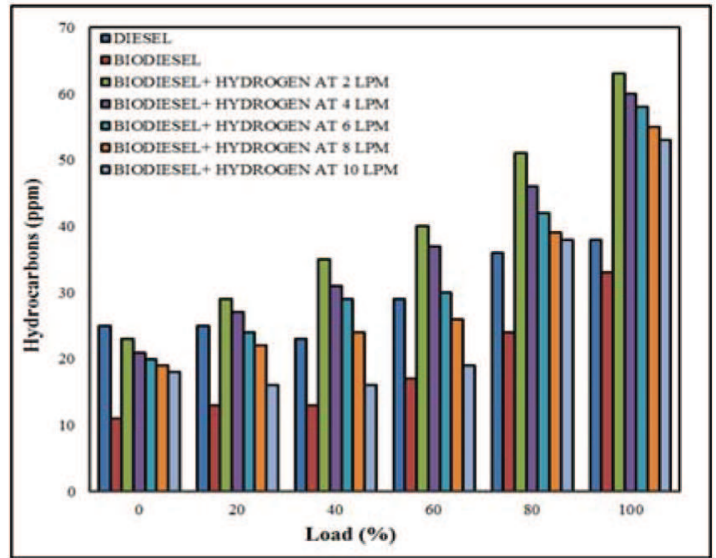

Fig. 5e Load Vs HC for biodiesel with hydrogen induction for $20 \%$ EGR

Hydrogen induction at 10 LPM provided $53 \mathrm{ppm}$ at $100 \%$ load Hydrogen induction to the biodiesel fueled engine with $30 \%$ EGR decreased the combustion temperature further than $20 \%$ EGR. Hydrogen induction at $10 \mathrm{LPM}$ provided $63 \mathrm{ppm}$ at full-loading conditions. Hydrogen induction at $10 \mathrm{LPM}$ provided $53 \mathrm{ppm}$ at $100 \%$ load. Hydrogen induction to the biodiesel fueled engine with $30 \%$ EGR decreased the combustion temperature further than $20 \%$ EGR. Hydrogen induction at $10 \mathrm{LPM}$ provided $63 \mathrm{ppm}$ at full-loading conditions. A maximum HC of 70 ppm was obtained at $100 \%$ load for 2 LPM hydrogen induction with 30\% EGR. Cold EGR technique was increased the HC emission at 10 LPM compared to neat diesel operation due to insufficient oxygen during combustion.

The EGR increased the amount of HC emission as shown in Figures $5 \mathrm{~d}$ and $5 \mathrm{e}$. Hydrogen induction to the biodiesel-fueled engine with $10 \%$ EGR decreased the combustion temperature. Hydrogen induction at 10 LPM provided HC of $34 \mathrm{ppm}$ at $100 \%$ load. Hydrogen induction to the biodiesel- fueled engine with $20 \%$ EGR decreased the combustion temperature. Hydrogen induction to the biodiesel-fueled engine with $10 \%$ EGR decreased the $\mathrm{CO}$ emission due to absence of carbon in hydrogen fuel. Hydrogen induction at $10 \mathrm{LPM}$ provided $0.03 \%$ by volume at $100 \%$ loading conditions. Hydrogen induction to the biodiesel-fueled engine with $20 \%$ EGR decreased CO emission. Hydrogen induction at 10 LPM provided CO to $0.03 \%$ by volume at $100 \%$ load. Hydrogen induction to the biodiesel-fueled engine with 30\% EGR decreased CO emission. Hydrogen induction at $10 \mathrm{LPM}$ provided CO to $0.03 \%$ by volume at $100 \%$ load. The carbon monoxide emission decreased due to the absence of carbon in hydrogen fuel.

\section{Conclusions}

The EGR reduced brake thermal efficiency by $1.31 \%, 2.06 \%$ and $2.65 \%$ respectively for $10 \%, 20 \%$ and $30 \%$ EGR, respectively compared with that of diesel, because of a decrease in combustion due to the addition of already burned inert gas as EGR. The brake specific energy consumption reduced by $588.17 \mathrm{~kJ} / \mathrm{kWh}, 1023.85 \mathrm{~kJ} / \mathrm{kWh}$ and 1062.31 $\mathrm{kJ} / \mathrm{kWh}$ respectively for 10,20 and $30 \%$ of EGR. The exhaust temperature was reduced by 38,74 and 120 ÚC for 10,20 and $30 \%$ of EGR, respectively.. The reduction in combustion temperature due to EGR addition resulted in NOx reduction. HC decreased by $4 \mathrm{ppm}$ for $10 \%$ EGR compared with diesel. The reduction of $\mathrm{CO}$ emission was found, when compared to diesel operation due to the addition of carbon free hydrogen fuel. The reason for reduction in $\mathrm{CO}_{2}$ emission was due to the absence of carbon in hydrogen and lower carbon content in biodiesel.

\section{References}

[1] Agarwal D, Singh SK, Agarwal AK (2011), Effect of exhaust gas recirculation (EGR) on performance, emissions, deposits and durability of a constant speed compression ignition engine. Appl Energy,88: 2900-07.

[2]Antunes GJM, Mikalsen R, Roskilly AP (2009), An experimental study of a direc injection compression ignition hydrogen engine. Int J Hydrogen Energy, 34: 651622.

[3]Boulifi NE, Bouaid A, Martinez M, Aracil J (2010), Process optimization for biodiese production from corn oil and its oxidative stability. Int J Chem Eng, 518070: 1-9. 
[4] Chaichan MT (2015), Performance and emission study of diesel engine using sunflowers oil-based biodiesel fuels. Int J Sci Eng Res, 6:260-69.

[5]Chaichan MT, Al Zubaidi DS (2012), Practical study of performance and emissions of diesel engine using biodiesel fuels. Arabic Univ Union J, 18:1-12.

[6] Ghazikhani M, Feyz ME, Joharchi A (2010), Experimental investigation of the exhaust gas recirculation effects on irreversibility and brake specific fuel consumption of indirect injection diesel engines. Appl Therm Eng, 30:1711-18.

[7] Liew C, Li H, Liu S, Besch MC, Ralston B, Clark N, (2012), Exhaust emissions of a $\mathrm{H}_{2}$ enriched

heavy-duty diesel engine equipped with cooled EGR and variable geometry turbocharger. Fuel, 91:155-63

[8] Lin CY, Lin HA (2007), Engine performance and emission characteristics of a threephase emulsion of biodiesel produced by per-oxidation. Fuel Process Technol, 88:35-41.

[9] Pradeep V, Sharma RP (2007), Use of hot EGR for NOx control in a compression ignition engine fuelled with bio-diesel from Jatropha oil. Renew Energy, 32:1136 54

[10] Sandalc T, Karag•oz Y. (2014), Experimental investigation of the combustion characteristics, emissions and performance of hydrogen port fuel injection in a diesel engine. Int J Hydrogen Energy, 39:18480-9

[11] Saravanan N, Nagarajan G, Dhanasekaran C, Kalaiselvan K (2008), An experimenta investigation on performance and emissions study with port injection using diesel as an ignition source for different EGR flow rates. Int J Hydrogen Energy, 33 4456-62.

[12]Shin B, Cho Y, Han D, Song S, Chun KM (2011). Hydrogen effects on NOx emissions and brake thermal efficiency in a diesel engine under low-temperature and heavyEGR conditions. Int J Hydrogen

Energy, 36:6281-91

[13] Song H, Song S. (2015), Predicting performance of a methane-fueled HCCI engine with hydrogen addition considering knock resistance. Int J Hydrogen Energy, 40:15749-59. 